\title{
A Demographic and Biochemical Analytic of Cases of G6PD Deficiency: A Cross-Sectional Study from the Middle East
}

\author{
Ahmed Al-Imam 1,2,3,4 \\ 1. CERVO Brain Research Center, University of Laval, Canada \\ 2. Department of Anatomy and Cellular Biology, College of Medicine, University of Baghdad, \\ Iraq. \\ 3. The Canadian Association for Neuroscience \\ 4. The Japanese Association of Anatomists
}

\section{CORRESPONDING AUTHOR}

Dr Ahmed Al-Imam:

Department of Anatomy and Cellular Biology,

College of Medicine, University of Baghdad,

Bab Al-Moadham, 10053, Baghdad, Iraq.

Email: tesla1452@gmail.com | a.m.al-imam@herts.ac.uk

Phone number: +964 (0) 7714338199

ResearchGate Account: https://www.researchgate.net/profile/Ahmed Al-Imam

Scopus Account: https://www.scopus.com/authid/detail.uri?authorId=57191594132

Scopus Author ID: 57191594132

\section{MANUSCRIPT METRICS}

Total number of words/ 3448

Total number of page/ 18

Total number of illustrations/ Two (2) tables and four (4) figures

Source of Funding: No external funding, this study was entirely self-funded.

Conflict of Interest: None 


\section{ABSTRACT \\ BACKGROUND}

G6PD deficiency is an inherited an X-linked recessive condition leading to insufficient levels of glucose6-phosphate dehydrogenase, thus causing hemolytic anaemia under certain conditions.

\section{METHODS}

Our study is explorative for cases admitted to Jordan University Hospital. The studied parameters include demographics, clinical manifestations, biochemical markers including $\mathrm{Hb}$ level, WBC count, liver enzymes, and blood grouping.

\section{RESULTS}

Most of the patients were admitted to the emergency unit (53.13\%). Individuals who were Rh-positive represented $57.81 \%$, while patients of $\mathrm{AB}$ blood group accounted for $75 \%$. The mean values were 4.81 years (age), 29.06 hours (time-to-hospital admission), 38.10 degree Celsius (temperature), $6.11 \mathrm{gm} / \mathrm{dl}$ (Hb), 13242.19 (WBC count), 343.20 U/L (S. ALP), and 50.98 IU/L (S. ALT). There was no significant difference between males and females or between favism-induced versus drug-induced hemolytic episodes. $\mathrm{AB}$ and $\mathrm{Rh}$ positive blood groups are of protective effect in relation to liver enzymes. Patients who were admitted to the hospital within 24 hours from having clinical manifestations had a better prognosis.

\section{CONCLUSION}

This study is the first inferential research on G6PD deficiency from the Middle East to explore cases from one of the largest healthcare centres in Jordan. The role of blood grouping should be investigated prospectively.

\section{KEYWORDS}

Glucosephosphate Dehydrogenase Deficiency; G6PD; ABO Blood-Group System; Middle East; Arabs. 


\section{INTRODUCTION}

Glucose-6-Phosphate Dehydrogenase (G6PD) Deficiency is the most common enzymatic disorder of genetic basis affecting the red blood cells (RBCs) of nearly 400 million individuals worldwide [1, 2]. It has a high prevalence in people of African, Asian, and Mediterranean descent. Therefore, the severity of G6PD deficiency can vary significantly among ethnic groups [2]. The World Health Organization (WHO) has classified G6PD deficiency into variants (class-I to class-V) based on the level of enzyme deficiency and the severity of hemolytic episode and its clinical manifestations. Class-I deficiency represents the most severe form of G6PD deficiency. G6PD deficiency in the region of the Mediterranean basin is usually a class-II deficiency, while class-III deficiency is due to defect in the gene G6PD A - Class IV and Class $\mathrm{V}$ are of no clinical significance [3].

The G6PD enzyme is part of the pentose monophosphate shunt. It catalyses the oxidation of glucose-6phosphate and the reduction of nicotinamide adenine dinucleotide phosphate (NADP+) to nicotinamide adenine dinucleotide phosphate (NADPH). NADPH maintains glutathione in its reduced form, which acts as a scavenger for oxidative metabolites [4]. G6PD deficiency is inherited as an X-linked recessive disorder similar to that of haemophilia and colourblindness $[2,4]$. The condition is generally asymptomatic, but the atmospheric exposure or ingestion of fava beans and certain chemicals including drugs, as well as bacterial or viral infectious agents can trigger an acute episode of hemolytic anaemia [4]. Infections are the most common triggers of $\mathrm{RBC}$ hemolysis via a reactive inflammatory response leading to the generation of free radicals in macrophages, which can diffuse into the RBCs causing oxidative damage [4,5]. Fortunately, symptoms of G6PD deficiency, including cardio-respiratory distress and pallor, typically disappear once the trigger is recognised or removed in parallel with management with blood transfusion and hemodynamic support for the patient $[2,3,5]$. G6PD deficiency appears to be a risk factor for the development of diabetes mellitus $[1,5]$.

This study aims to explore the epidemiology of G6PD deficiency in the Arabic ethnicity from the Hashemite Kingdom of Jordan. The demographic parameters of patients will be examined in addition to data on blood grouping, blood film, liver function tests (LFT), family history of G6PD deficiency and neonatal Jaundince, and neural manifestations of interest specifically lethargy, and poor feeding. 


\section{MATERIALS AND METHODS}

This study is purely observational and cross-sectional in design. It was conducted from $22^{\text {nd }}$ of March 2015 to the $24^{\text {th }}$ of January 2016. The cross-sectional analytics targeted cases of G6PD deficiency admitted and diagnosed for the $1^{\text {st }}$ time at Jordan University Hospital in Amman-Jordan. All cases admitted to the hospital within the specified timeframe were included in this study (no exclusion). The study has been conducted via a joint collaboration between the University of Jordan and the University of Baghdad. The project code is G6PD-1 and it has the Ethical approval no. 620-73, issued on the 15th of May 2015. The approval is under the authority of the dean office at the College of medicine at the University of Baghdad. All individuals were of the Arab ethnicity from the Middle East who are permanent residents of Jordan. Data collection was based on a personal interview (5-10 minutes) conducted by a professional specialist pharmacist and a physician who have been well-trained to avoid biases including selection and interpretation errors.

The interviews took place either in the emergency room (ER), paediatrics outpatient clinic, or the paediatrics department. The collected data included parameters representing the date of incident $\left(1^{\text {st }}\right.$ incident of hemolytic anaemia due to G6PD deficiency), time-to-hospital admission (TTH), age, family history of G6PD deficiency, and past medical history of neonatal jaundice. Clinical signs and symptoms were also explored including body temperature in degree Celsius (rectally-measured or corrected), vomiting, and other manifestations including poor feeding, lethargy, itching, anorexia, jaundice, abdominal pain, and dark discolouration of urine and jaundice. The triggering agents for hemolytic anaemia were screened and were attributed either due to medicinal chemicals (drug-induced) or due to fava beans which can be either fresh (f), dry (d), or cooked (c). The diagnosis of G6PD deficiency was established based on diagnostic features from patients and family history, clinical examination, blood film, and diagnostic biochemical markers. Biochemical workup was carried out at the laboratories of the Hospital using standardised kits. Biochemical tests included blood grouping (ABO and $\mathrm{Rh}$ ), haemoglobin level (Hb), total leukocytes count (WBC count), and liver enzymes (S. ALP, S. ALT). These enzymes were assessed via enzyme-linked immunosorbent assay (ELISA). The units of measurement were in years (age), hours (TTH), degree Celsius (temperature), $\mathrm{gm} / \mathrm{dl}(\mathrm{Hb}), \mathrm{U} / \mathrm{L}$ (S. ALP), and IU/L (S. ALT). Normative values were standardised for patient's age and based on manufacturer instructions already provided with the utilised kit technology. All parameters were tabulated into a database which was subsequently analysed via the appropriate statistical methods and tests. The parametric tabulations were later exploited for stratification, blocking, and sub-grouping for detailed statistical analyses and hypotheses testing. The level-of-evidence for this study is estimated to be of level3 in compliance with the categorisation scheme of level-of-evidence imposed by the Oxford Center for Evidence-Based Medicine [6, 7]. A systematic review of the literature was carried out on medical and 
paramedical databases of literature including NCBI-PubMed/Medline, the Cochrane Library, Embase, EBSCO, Google Scholar, ResearchGate, Academia, and Sci-Hub. The grey literature databases were also consulted. The reviewed literature of interest was subsequently scrutinised for credibility and reliability via the implementation of the appropriate tools of critical appraisal $[8,9]$.

\section{RESULTS}

The total number of patients included in the cross-sectional analytics was sixty-four $(n=64)$, all were from the Arab ethnicities inhabiting the capital city of Amman in the Hashemite Kingdom of Jordan. Male patients accounted for $62.5 \%$. Approximately, eighty percent of patients were of an age ranging in between six months to five and half years (5.5 years). The youngest patient was six months old while the oldest was eleven years old. (Figure 1). The majority of patients (76.56\%) were admitted to the hospital within 24 hours from onsets of symptomatic manifestations of the acute hemolytic anaemia, while the rest $(21.88 \%)$ were admitted within 48 hours, and only one patient (1.56\%) was admitted within 12 hours. Most of the patients were interviewed first at the ER (53.13\%), department of paediatrics (42.19\%), or at the paediatrics outpatient clinic (4.69\%). Individuals who were Rh-positive represented $57.81 \%$ of all patients. Concerning ABO blood grouping, patients were allocated to all four blood groups including group-A $(6.25 \%)$, group B (12.5\%), group $\mathrm{O}(6.25 \%)$, and group $\mathrm{AB}(75 \%)$.

For the tabulated parameters, mean values (+/- standard deviation) were $4.81+/-2.80$ years (age), $29.06+/-$ 10.21 hours (TTH), $38.10+/-1.09$ degree Celsius (temperature), $6.11+/-0.67 \mathrm{gm} / \mathrm{dl}(\mathrm{Hb}), 13242.19+/-$ 3070.26 cell per cubic centimeter (WBC count), $343.20+/-41.67$ U/L (S. ALP), and 50.98 +/- 12.80 IU/L (S. ALT). Males averaged 4.66 years (Age), 38.10 (temperature), 6.08 (Hb), 13025 (WBC), 337.26 (S. ALP), and 49.45 (S. ALT). Females averaged 5.06 years (age), 38.09 (temperature), 6.17 (Hb), 13604.17 (WBC count), 353.08 (S. ALP), and 53.54 (S. ALT). Blood films from all patient displayed normochromic normocytic anaemia with hemolysed red blood cells (RBCs). There was no statistically significant difference based on sex ( $p$-value=0.330). Similarly, there was no significant difference concerning the same parameters in between incidents of acute hemolytic anaemia due to favism (68.75\% of all patients) or medicinal chemicals $(31.25 \%)(\mathrm{p}=0.347)$. Medicinal chemicals inducing acute hemolytic anaemia in G6PD deficient patients were limited to amikacin, Ascorbic Acid, aspirin, and trimethoprim. There was no hemolytic episode triggered by dry fava beans, while those cases triggered by cooked beans and fresh fava beans represented $42.19 \%$ and $26.56 \%$ of the total number of G6PD deficient patients admitted to the hospital.

Statistical outliers were only evident for liver enzyme levels and time-to-hospital admission (Figure 2). Outliers included hospitalisation either after 12 or 48 hours of symptomatic manifestations (TTH), enzyme 
level equal or less than 224.5 U/L (S. ALP), and equal or less than 20 IU/L (S. ALT). In other words, normal liver enzymes were not usually encountered in acutely-presented cases of G6PD deficient individuals. No statistical outliers were detected for age, temperature, level of $\mathrm{Hb}$, and total WBC count. Most patients were admitted to hospital during March, June, October, and November in 2015 (Figure 3). No patients were admitted to the hospital during the August 2015.

There were no significant differences in between male and female patients regarding age, temperature, $\mathrm{Hb}$ level, WBC count, and liver enzymes (Table 1 and 2). The same applies to patients with positive versus negative family history of G6PD deficiency. However, patients with positive family history had a significantly higher temperature (38.23 versus $37.64, p$-value $=0.058$ ). Analogously, patients with positive history of neonatal jaundice had a higher temperature (38.41 versus $37.81, \mathrm{p}=0.027$ ), and a significantly lower level of haemoglobin at $90 \% \mathrm{CI}$ (5.85 versus $6.26, \mathrm{p}=0.066)$, while age and liver enzymes were consistently similar in between the two groups (Table 1).

Although AB blood group is not frequently encountered in the population, it appeared to be clustered (75\%). Accordingly, it was hypothesised that $\mathrm{ABO}$ and $\mathrm{Rh}$ blood group could be a significant factor interacting with other tabulated parameters including severity of manifestations, Hb level, and liver enzymes (Table 2). Patients with $A B$ blood group had significantly lower levels of S. ALP enzyme compared to patients allocated to other ABO blood groups (336.99 versus 361.81, $\mathrm{p}=0.018$ ). Concerning favism and at $90 \% \mathrm{CI}$, patients who were triggered by cooked fava beans were significantly older than those who were triggered by medicinal chemicals (drug-induced) (5.84 years versus 3.92, $\mathrm{p}=0.077$ ) which means that drug-induced hemolytic episode will usually present earlier in life than fava bean-induced episodes. Concerning prognosis and based on the time-of-hospital admission, it appeared that patients who were admitted at 48 hours had significantly lower haemoglobin level than those who were hospitalised at 24 hours (5.77 versus $6.21, \mathrm{p}=0.044$ ). The timing of admission to hospital can be a critical prognostic factor in managing patient with G6PD deficiency.

Additional confirmatory statistical testing was run using Chi-Square test to validate the previous hypothesis on blood grouping. The aim was to test the association between blood grouping ( $\mathrm{ABO}$ and $\mathrm{Rh}$ ) versus $\mathrm{Hb}$ level (below average-Hb versus above average-Hb within the studied sample), WBC count (Leukocytosis versus normal WBC count), temperature (febrile versus non-febrile patients), liver enzymes (elevated versus non-elevated), and triggering event (drug-induced versus favism-induced), hospitalization site (ER versus other departments). Accordingly, a statistical difference was significant only for ABO blood grouping versus S. ALP enzymatic level at (Relative Risk $(\mathrm{RR})=0.725$ and $p$-value $=0.051$ ) which mean that $\mathrm{AB}$ blood group is protective concerning the normative value of this specific liver enzyme. Similarly, AB blood group was also protective for S. ALT liver enzyme $(\mathrm{RR}=0.686, \mathrm{p}<0.001)$. On the other hand, Rh- 
positive blood group was found to have a protective effect from the favism-induced breakdown of RBCs $(\mathrm{RR}=1.948, \mathrm{p}=0.013)$ in G6PD-deficient patients. Modelling via linear regression failed to detect a strong positive or strong negative correlations between any of the tabulated parameters. However, a statistically significant $(\mathrm{p}<0.01)$ and a modest degree of positive relationship was found in between the levels of S. ALP and the other two liver enzymes $\left(R^{2}\right.$ score $\left.=0.0993\right)$ (Figure 4$)$.

To summarise, G6PD deficient patients from Jordan were hospitalised during specific months of the year, and most of them were admitted to the ER within the 24 hours from the onset of the acute hemolytic episode. Those episodes were the first presentation underlying a G6PD deficiency status which was confirmed via history, clinical examination, and laboratory investigations. Most of the patients were sensitive to cooked beans and fresh beans as well as a smaller fraction of patients whom hemolytic episodes were triggered by some medicinal chemicals. Almost three-quarters of patients were of $\mathrm{AB}$ blood group which was found to have a protective effect on liver enzymes. The prognosis seems to be worse for those with delayed hospitalisation.

\section{DISCUSSION}

Future studies should attempt to collect data from more than one centre (multi-centre) and more than one country from the Basin of the Mediterranean sea, the Arabian Gulf region, and the Middle East. Other ethnicities, in addition to Arabs, should also be included via proper stratification of the studied sample. Specific enzyme assays, including G6PD enzyme assay, should be implemented. Subsequent studies should attempt to unravel the mystery of link, conveyed via statistical analysis of our study, between blood grouping and liver enzymes. Experimental and quasi-experimental study designs, including therapeutics and gene therapeutics in parallel with observational analyses, will actively promote the level-of-evidence of future research $[10,11]$. The incorporation of concepts of machine learning and real-time analytics will provide an enormous impact of the level-of-evidence of studies as well as offer a preemptive warning system for mass casualties due to hemolytic anaemias clustered in a specific region of the world [12, 15]. The benefits for public health and the economy will be colossal by sparing workforce, and other resources including financial ones.

G6PD deficiency is not only the most common red blood cell enzymopathy but also represents the most common of all clinically significant enzyme defects of human biology as a whole [16]. G6PD deficiency constitutes a significant public health problem in the Middle East $[17,18]$. The highest incidence of G6PD deficiency has been described in Sardinia [19]. G6PD deficiency is still a significant health problem in Jordan. The prevalence of G6PD deficiency in the north of Jordan was estimated to be around 5.5\% while $17 \%$ of children admitted to princess Rahma teaching hospital with acute hemolytic anaemia due to G6PD 
deficiency were females [20]. G6PD deficiency is a public health problem that has been a predominant cause of severe hemolytic anaemia requiring urgent hospitalisation in young Palestinian children in Gaza strip [21]. The highest prevalence of this enzymatic defect was reported among sub-Saharan African countries [22]. G6PD deficiency is also common in some provinces of Iran as fava beans represent an everyday food though Iran is considered as a moderately high incidence area for G6PD deficiency [23].

Meloni and colleagues have found that the highest incidence of favism or drug-induced hemolytic anaemia occurred in children aged between 2-6 years while children below two years of age made up only $4.5 \%$ whereas those over six years of age constituted 22.3\% [19]. Another study has found that most victims (81.6\%) experienced their first haemolytic episode before the age of 10 years [24]. Our study demonstrated that males are more than females (62.5\%) which is in line with prior research efforts. G6PD deficiency shows full expression in heterozygous males and homozygous females [16, 18, 25]. Another research reported the frequency of the enzyme deficiency in male children (76\%) was higher than in females (24\%). However, the incidence of the severe form of the enzyme deficiency in female children was considerably lower [16].

In our study, most of the patients were admitted to hospital during March, June, October, and November in 2015. Prior research ventures have a reasonable explanation for the high incidence of favism-induced hemolytic anaemia during the spring as it can be correlated with harvesting season of fava beans as well as local fava beans-containing foods are cooked and consumed [18, 19]. The winter season, however, was the second seasonal peak (14.56\%). It has been presumed that G6PD deficiency hemolytic attack could be triggered by an infectious agent, mainly viral, during the springtime and in specific geographic locations of the world [23]. Accordingly, it is hypothesised that the pathogenic agent could be associated in some way with the fava bean plant. Therefore, individuals with severe G6PD deficiency, especially the Mediterranean type, who get exposed to this pathogen for the first time may develop severe hemolysis [24].

Most patients in our observational analysis were interviewed in the emergency department, while others in paediatrics department and outpatient units. The American Academy of Pediatrics showed that the lack of access to primary care physicians in the local community was associated with higher emergency department admissions $[18,26]$. Children requiring emergency care have unique needs while those younger than three years of age represent the most considerable proportion of medically related visits [27]. All those who were admitted to hospital had normochromic normocytic anaemia with fragmented RBCs due to hemolysis in the blood film. Morphologic findings are generally unremarkable except after 12-24 hours [28]. The anaemia is primarily due to intravascular hemolysis [29]. 
Our cross-sectional analytic revealed that dry fava beans triggered no haemolytic episode which is in harmony with previous studies as fresh fava beans are known to be the leading cause for the development of acute hemolytic anaemia [19]. Further, the high protein contents and inexpensive fava beans, that are highly available in the region of the Mediterranean basin render them a valuable ingredient of regular diet [18]. Madanat and coworkers also found that the primary triggering factor of hemolysis was the ingestion of fresh uncooked fava beans [20]. Similarly, Meloni and coauthors confirmed that the highest percentage (94.4\%) of hemolytic crises was due to fresh fava beans [19]. On the other hand, Pamba and colleagues, they confirmed that several factors could further influence the severity of hemolytic anaemia including the pharmacodynamics and pharmacokinetics of the chemical trigger, the dose, the typology of G6PD mutation, the age of the patient, and the coexisting medical conditions [30].

Following a trigger event, RBC hemolysis does not usually begin until 24 hours of exposure and may continue for several days although the onset of hemolysis in favism may by more abrupt compared to druginduced hemolytic attacks [31]. In severe hyperbilirubinemia where the total serum bilirubin is more than $25 \mathrm{mg} / \mathrm{dl}$, there is a risk for severe complications including kernicterus and intellectual handicapping [32]. Behjati-Ardakani and Sedaghat have also found that as many as one-third of all males with neonatal jaundice had G6PD deficiency although it was found that neonatal jaundice was significantly lower among subjects of African Ancestry who are living in the United States which indicate an environmental-genetic interaction [32].

Prior research attempts have shown that haemoglobin levels lower than $7 \mathrm{~g} / \mathrm{dl}$ were found in $74.15 \%$ of males and $53.45 \%$ of females $[19,30]$. Conclusive results from our study highlight that three-quarters of patients are of blood group $\mathrm{AB}$ which is contrary to that of the healthy population where $\mathrm{AB}$ blood type is not frequently encountered [33,34]. This fact should be intensively explored in subsequent studies and from the perspective of a molecular biologist.

Identification of factors that may influence patients' outcome at the institutional level is crucial for quality control purposes and benchmarking. In our study, patients who were admitted within 48 hours, from the onset of the appearance of symptoms, had significantly lower haemoglobin level than those who were hospitalised within 24 hours. However, Honar and colleagues did not report any significant correlation between the haemoglobin level, hospitalisation, hemoglobinuria, the number of blood transfusions, and the clinical manifestation [35]. Regarding the clinical aspects of G6PD deficiency, anaemia and hemoglobinuria associated with general malaise weakness, cephalea and vomiting were are the most evident signs [19]. Typically a hemolytic attack initiates with malaise, weakness, and abdominal or lumbar pain [29]. These manifestations are associated with severe hemolysis due to haemoglobin urea or nitric oxide depletion, while vomiting can be a significant predictor of an acute and drastic haemolytic episode 
[16]. Subsequently and after an interval of several hours to 2-3 days, the patient usually develops jaundice and dark urine due to hemoglobinuria [16, 29].

Other clinical manifestations include an enlarged spleen and liver [17, 23, 32]. Concerning liver function, inherently defective liver enzymes can play a critical role in influencing the development of severe hyperbilirubinemia [16]. The chief complaints of patients can be described as a triad of urine discolouration, jaundice, and vomiting (59\%) which can be considered as the triangle of classic favism-triggered hemolysis. $[18,29,36]$. Nevertheless, Fever remains the most common concern prompting parents to present their child to the emergency department $[1,10]$. Our research emphasises the predominant existence of the G6PD deficiency among Jordanian population, which justifies the necessity of the policy leaders of the Jordanian public health and health services to establish national programs as well as international collaborations for newborn screening of G6PD deficiency.

\section{CONCLUSIONS}

Our study is the first of its kind to integrate and extrapolate a statistical inference on ABO and Rh blood grouping in connection with the pathophysiology of the disease especially about the elevation of specific liver enzymes. The levels of haemoglobin, the timing of hospitalisation, the existence of a positive family history of the disease, and history of neonatal jaundice, can be given specific "weight" in an updated formula for the prognosis of patients with G6PD deficiency.

The study does have some limitations including the collection of data from one centre, reliance on pure observational analyses rather than an experimental approach, lack of use of G6PD enzyme assay, and the inclusion of one ethnic group. Additionally, the study did not incorporate the use of real-time or predictive analytics of data. The later can revolutionise epidemiological studies via the integration of concepts of big data in parallel with machine learning and automated data collection. 


\section{REFERENCES}

1. Walker BR, Colledge NR. Davidson's Principles and Practice of Medicine, $23^{\text {rd }}$ ed. The Netherlands: Elsevier; 2018. Pages: 948 - 949

2. Marshall WJ, Lapsley M, Day A, Ayling R. Clinical Biochemistry E-Book: Metabolic and Clinical Aspects. Elsevier Health Sciences; 2014 Mar 5.

3. Luzzatto L, Nannelli C, Notaro R. Glucose-6-phosphate dehydrogenase deficiency. Hematol Oncol Clin. 2016 Apr 1;30(2):373-93.

4. Marcdante K, Kliegman RM. Nelson Essentials of Pediatrics E-Book. Elsevier Health Sciences; 2014 Feb 25.

5. Ombrone D, Giocaliere E, Forni G, Malvagia S, la Marca G. Expanded newborn screening by mass spectrometry: new tests, future perspectives. Mass Spectrom Rev. 2016 Jan;35(1):71-84.

6. Oxford Centre for Evidence-Based Medicine. OCEBM Levels of Evidence. Available at https://www.cebm.net/2016/05/ocebm-levels-of-evidence/ (accessed 20 July 2018).

7. Greenhalgh T, Howick J, Maskrey N. Evidence based medicine: a movement in crisis?. BMJ. 2014 Jun 13;348:g3725.

8. Rosenkoetter U, Tate RL. Assessing features of psychometric assessment instruments: A comparison of the COSMIN checklist with other critical appraisal tools. Brain Impair. 2018 Mar;19(1):103-18.

9. Zeng X, Zhang Y, Kwong JS, Zhang C, Li S, Sun F, Niu Y, Du L. The methodological quality assessment tools for preclinical and clinical studies, systematic review and meta-analysis, and clinical practice guideline: a systematic review. J Evid Based Med. 2015 Feb;8(1):2-10.

10. Deaton A, Cartwright N. Understanding and misunderstanding randomized controlled trials. Soc Sci Med. 2017 Dec 25.

11. Moher D, Shamseer L, Clarke M, Ghersi D, Liberati A, Petticrew M, Shekelle P, Stewart LA. Preferred reporting items for systematic review and meta-analysis protocols (PRISMA-P) 2015 statement. Syst Rev. 2015 Dec;4(1):1.

12. Witten IH, Frank E, Hall MA, Pal CJ. Data Mining: Practical machine learning tools and techniques. Morgan Kaufmann; 2016 Oct 1.

13. Bottou L. From machine learning to machine reasoning. Mach Learn. 2014 Feb 1;94(2):133-49.

14. Gandomi A, Haider M. Beyond the hype: Big data concepts, methods, and analytics. Int J Inform Manag. 2015 Apr 1;35(2):137-44.

15. Steele B, Chandler J, Reddy S. Real-time Analytics. In Algorithms for Data Science 2016 (pp. 381-401). Springer, Cham. 
16. Al-Sweedan SA, Jdaitawi H, Khriesat WM, Khader YY, Al-Rimawi HS. Predictors of severe hemolysis in patients with glucose-6-phosphate dehydrogenase deficiency following exposure to oxidant stresses. Hematol Oncol Stem Cell Ther. 2009 Apr 1;2(2):354-7.

17. Leinisch F, Mariotti M, Rykaer M, Lopez-Alarcon C, Hägglund P, Davies MJ. Peroxyl radicaland photo-oxidation of glucose 6-phosphate dehydrogenase generates cross-links and functional changes via oxidation of tyrosine and tryptophan residues. Free Radic Biol Med. 2017 Nov 1;112:240-52.

18. Khaliq AA, Broyles RW. Hospital admissions: who is admitted through the emergency department?. Health Serv Manage Res. 2006 Feb 1;19(1):13-22.

19. Meloni T, Forteleoni G, Dore A, Cutillo S. Favism and hemolytic anemia in glucose-6-phosphate dehydrogenase-deficient subjects in North Sardinia. Acta Haematol. 1983;70(2):83-90.

20. Al-Rimawi HS, Garaybah M, Al-Alimi AG, Amarin ZO. Glucose-6-Phosphate Dehydrogenase Activity in Jordanian Female Children with Acute Hemolytice Crises. Jordan Med J. 2007; 41(4). Available at https://journals.ju.edu.jo/JMJ/article/view/1086.

21. Sirdah MM, Al-Kahlout MS, Reading NS. National G6PD neonatal screening program in Gaza Strip of Palestine: rationale, challenges and recommendations. Clin Genet. 2016 Sep 1;90(3):1918.

22. Nkhoma ET, Poole C, Vannappagari V, Hall SA, Beutler E. The global prevalence of glucose-6phosphate dehydrogenase deficiency: a systematic review and meta-analysis. Blood Cells Mol Dis. 2009 May 1;42(3):267-78.

23. Eghbalian F, Monsef AR. Evaluation of glucose-6-phosphate dehydrogenase deficiency without hemolysis in icteric newborns. Iran J Pediatr. 2007;17(1):36-40.

24. Ahmed SN. Do favic patients resume fava beans ingestion later in their life, a study for this, and a new hypothesis for favism etiology. Hematol Oncol Stem Cell Ther. 2013 Mar 1;6(1):9-13.

25. Beutler E. G6PD: population genetics and clinical manifestations. Blood Rev. 1996 Mar $1 ; 10(1): 45-52$.

26. Bourgeois FT, Monuteaux MC, Stack AM, Neuman MI. Variation in emergency department admission rates in US children's hospitals. Pediatrics. 2014 Sep 1;134(3):539-45.

27. Alazmi MA, Elhassanien AF. Reduction of pediatric emergency hospital admissions by a change in pediatric emergency department policy. J Emerg Trauma Shock. 2013 Jul;6(3):209.

28. Ford J. Red blood cell morphology. Int J Lab Hematol. 2013 Jun 1;35(3):351-7.

29. Luzzatto L. Glucose 6-phosphate dehydrogenase deficiency: from genotype to phenotype. Hematologica 2006; 91(10). 
30. Pamba A, Richardson ND, Carter N, Duparc S, Premji Z, Tiono AB, Luzzatto L. Clinical spectrum and severity of hemolytic anemia in glucose 6-phosphate dehydrogenase-deficient children receiving dapsone. Blood. 2012 Nov 15;120(20):4123-33.

31. Beutler E. G6PD deficiency. Blood. 1994 Dec 1;84(11):3613-36.

32. Behjati-Ardakani S, Sedaghat AN. The association between G6PD deficiency and total serum bilirubin level in icteric neonates. Acta Medica Iranica. 2007;45(3):233-5.

33. Yamamoto M, Cid E, Yamamoto F. Crosstalk between ABO and Forssman (FORS) blood group systems: FORS1 antigen synthesis by ABO gene-encoded glycosyltransferases. Scientific reports. 2017 Jan 30;7:41632.

34. Butt SJ, Malik S, Malik H, Butt AJ. ABO and Rhesus Blood Grouping in Voluntary Blood Donors and its gender association. Pak J Med Health Sci. 2018 Jan 1;12(1):268-71.

35. Honar N, Javanmardi H, Saki F, Rezaeefard A, Shahriari M. Clinical Manifestations of Acute Hemolysis in Children with Glucose-6-Phosphate Dehydrogenase Deficiency in Fars Province, Iran. Int J Pediatr. 2018 Apr 1;6(4):7489-94.

36. Weng YH, Chou YH, Lien RI. Hyperbilirubinemia in healthy neonates with glucose-6-phosphate dehydrogenase deficiency. Early Hum Dev. 2003 Apr 1;71(2):129-36. 
Table 1. Descriptive and Inferential Statistics based on Sex (upper), Family History (middle), and History of Neonatal Jaundice (Lower).

\begin{tabular}{lccc}
\hline & \multicolumn{2}{c}{ Mean } & Inference \\
\hline & Female & Male & $p$-value \\
\hline Age & 5.06 & 4.66 & 0.590 \\
\hline Fever & 38.09 & 38.10 & 0.958 \\
\hline $\mathrm{Hb}$ & 6.17 & 6.08 & 0.603 \\
\hline $\mathrm{WBC}$ & 13604.17 & 13025.00 & 0.445 \\
\hline ALP & 353.08 & 337.26 & 0.109 \\
\hline ALT & 53.54 & 49.45 & 0.181 \\
\hline
\end{tabular}

\begin{tabular}{cccc}
\hline & \multicolumn{2}{c}{ Mean } & Inference \\
\hline & -ve Family Hx & +ve Family Hx & $p$-value \\
\hline Age & 4.22 & 4.98 & 0.353 \\
\hline Fever & 37.64 & 38.23 & 0.058 \\
\hline $\mathrm{Hb}$ & 6.14 & 6.10 & 0.843 \\
\hline $\mathrm{WBC}$ & 13625.00 & 13135.00 & 0.531 \\
\hline $\mathrm{ALP}$ & 356.71 & 339.41 & 0.117 \\
\hline $\mathrm{ALT}$ & 50.21 & 51.20 & 0.837 \\
\hline
\end{tabular}

\begin{tabular}{lccc}
\hline & \multicolumn{2}{c}{ Mean } & Inference \\
\hline & -ve Hx & +ve Hx & $p$-value \\
\hline Age & 4.33 & 5.32 & 0.160 \\
\hline Fever & 37.81 & 38.41 & 0.027 \\
\hline $\mathrm{Hb}$ & 6.26 & 5.95 & 0.066 \\
\hline WBC & 13356.06 & 13120.97 & 0.763 \\
\hline ALP & 344.23 & 342.10 & 0.837 \\
\hline ALT & 50.18 & 51.84 & 0.605 \\
\hline
\end{tabular}


Table 2. Descriptive and Inferential Statistics Based on ABO Blood Grouping ( $1^{\text {st }}$ table $)$, Favism ( $\left.2^{\text {nd }}\right)$, Drug-induced Hemolysis $\left(3^{\text {rd }}\right)$, and Time-to-Hospital Admission $\left(4^{\text {th }}\right)$.

\begin{tabular}{lccc}
\hline \multicolumn{2}{c}{ Mean } & Inference \\
\hline Age & 4.63 & 4.87 & 0.794 \\
\hline Fever & 38.31 & 38.03 & 0.432 \\
\hline $\mathrm{Hb}$ & 6.09 & 6.11 & 0.915 \\
\hline $\mathrm{WBC}$ & 12453.13 & 13505.21 & 0.204 \\
\hline ALP & 361.81 & 336.99 & 0.018 \\
\hline ALT & 55.00 & 49.65 & 0.187 \\
\hline
\end{tabular}

\begin{tabular}{lcccccc}
\hline \multicolumn{6}{c}{ Mean } & \multicolumn{3}{c}{$p$-value } \\
\hline & -ve & +ve $(\mathrm{F})$ & +ve $(\mathrm{C})$ & -ve vs. +ve(F) & -ve vs. +ve(C) & +ve(F) vs. +ve(C) \\
\hline Age & 3.92 & 4.79 & 5.48 & 0.333 & 0.077 & 0.389 \\
\hline Fever & 38.05 & 38.18 & 38.08 & 0.740 & 0.921 & 0.793 \\
\hline $\mathrm{Hb}$ & 6.08 & 6.12 & 6.13 & 0.849 & 0.795 & 0.952 \\
\hline $\mathrm{WBC}$ & 12737.50 & 13014.71 & 13759.26 & 0.795 & 0.295 & 0.408 \\
\hline ALP & 343.43 & 350.88 & 338.19 & 0.516 & 0.698 & 0.269 \\
\hline ALT & 49.90 & 51.18 & 51.67 & 0.782 & 0.646 & 0.905 \\
\hline
\end{tabular}

\begin{tabular}{lccc}
\hline & \multicolumn{2}{c}{ Mean } & Inference \\
\hline & Drug-induced -ve & Drug-induced +ve & $p$-value \\
\hline Age & 3.92 & 5.22 & 0.107 \\
\hline Fever & 38.05 & 38.12 & 0.817 \\
\hline $\mathrm{Hb}$ & 6.08 & 6.13 & 0.794 \\
\hline $\mathrm{WBC}$ & 12737.50 & 13471.59 & 0.422 \\
\hline $\mathrm{ALP}$ & 343.43 & 343.09 & 0.977 \\
\hline ALT & 49.90 & 51.48 & 0.665 \\
\hline
\end{tabular}

\begin{tabular}{lccc}
\hline & \multicolumn{2}{c}{ Mean } & Inference \\
\hline & TTH $(48 \mathrm{hr})$ & TTH $(24 \mathrm{hr})$ & $p$-value \\
\hline Age & 5.67 & 4.55 & 0.211 \\
\hline Fever & 38.07 & 38.10 & 0.928 \\
\hline $\mathrm{Hb}$ & 5.77 & 6.21 & 0.004 \\
\hline WBC & 12550.00 & 13454.08 & 0.347 \\
\hline ALP & 345.40 & 342.52 & 0.865 \\
\hline ALT & 53.53 & 50.20 & 0.413 \\
\hline
\end{tabular}




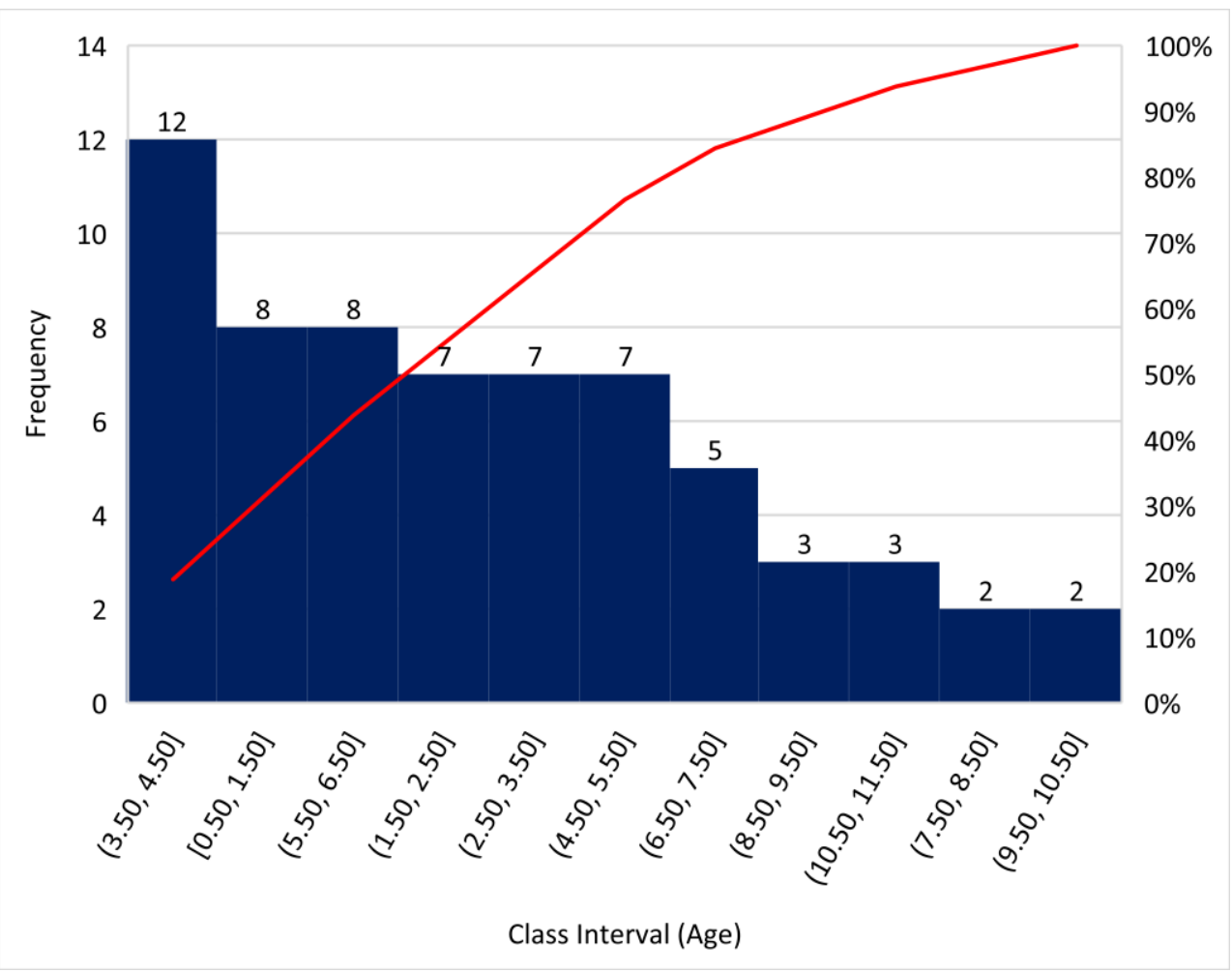

Figure 1. Frequency Distribution and Class Interval for Age (years). 


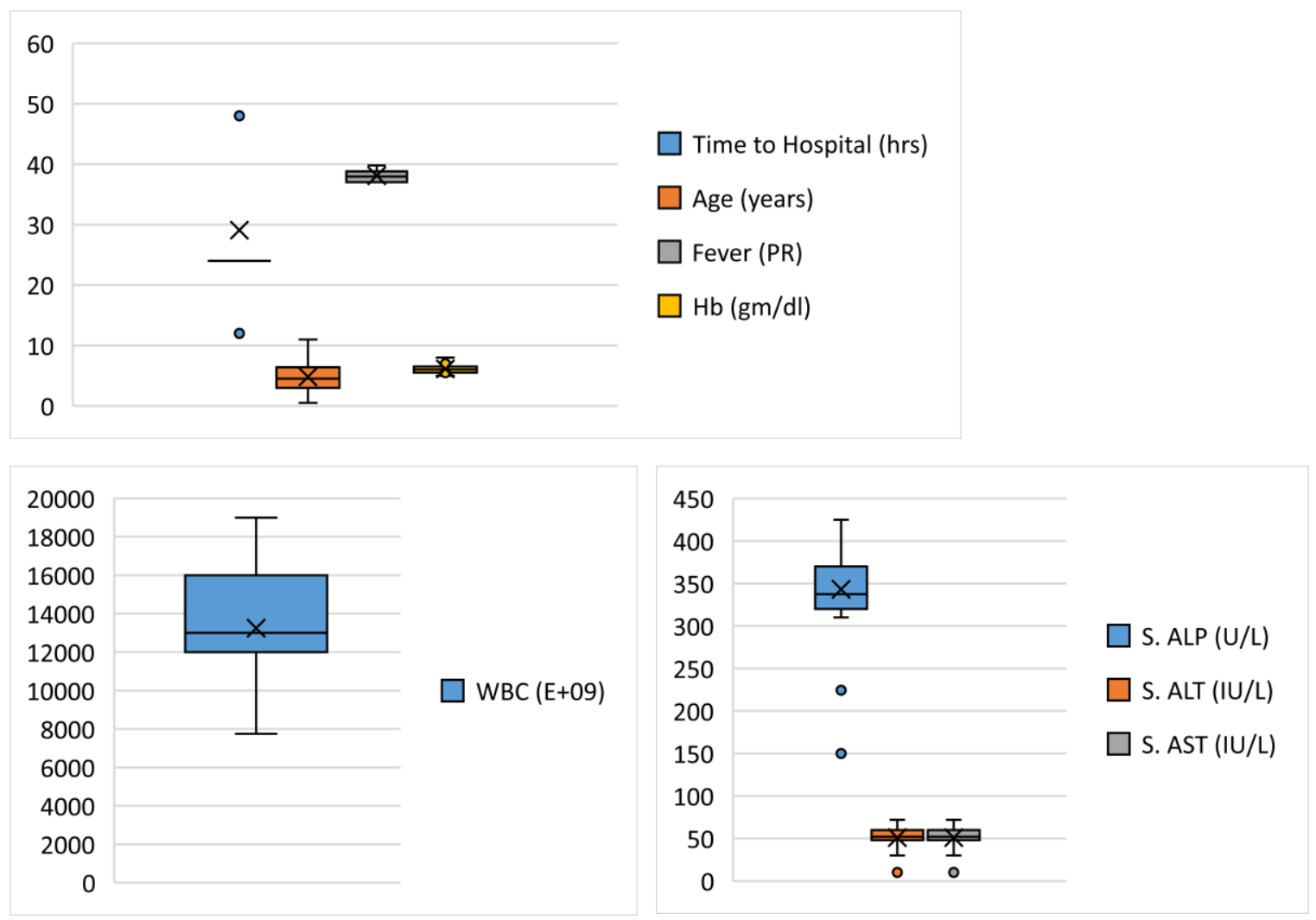

Figure 2. Boxplot Presentation: Demographics, WBC Count, and Liver Enzymes. 


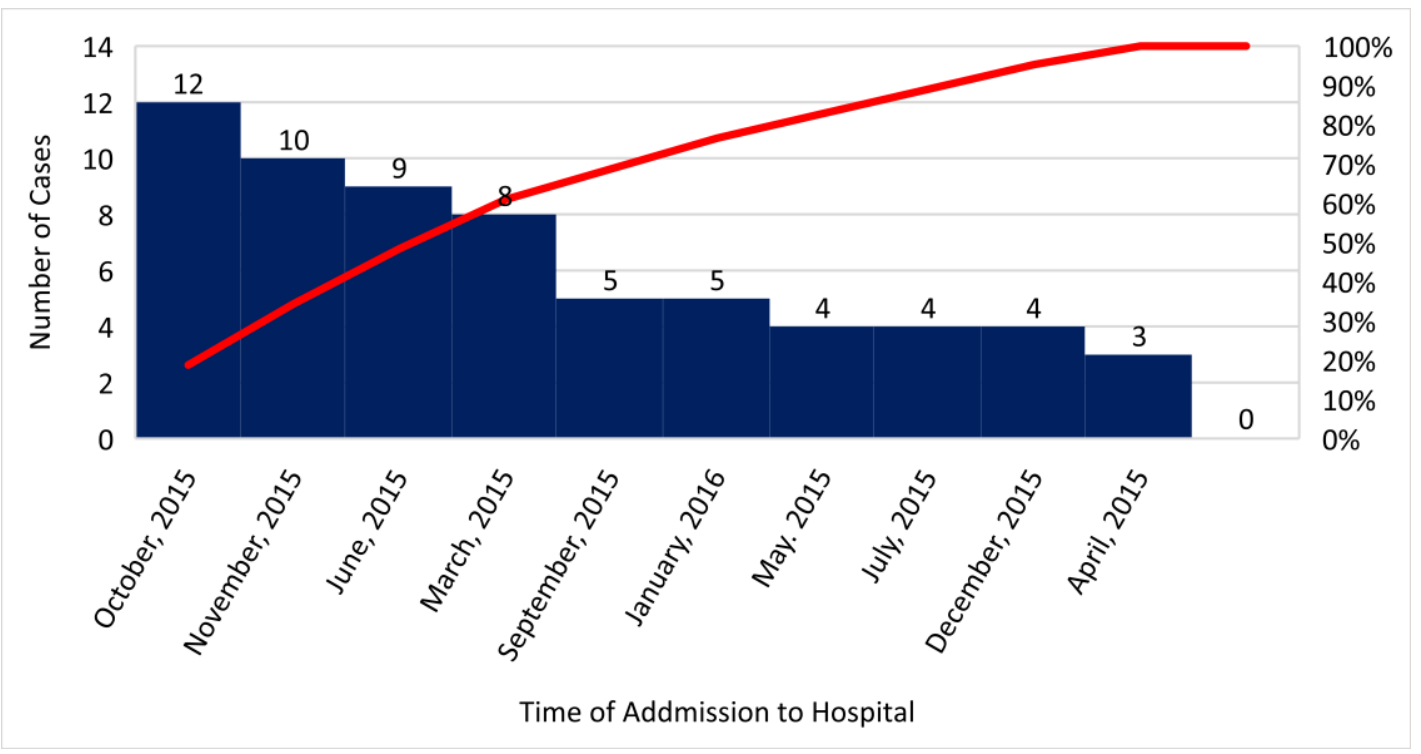

Figure 3. Descriptive Parameters: Age (years) versus Timing of Interview (time of hospitalization). 


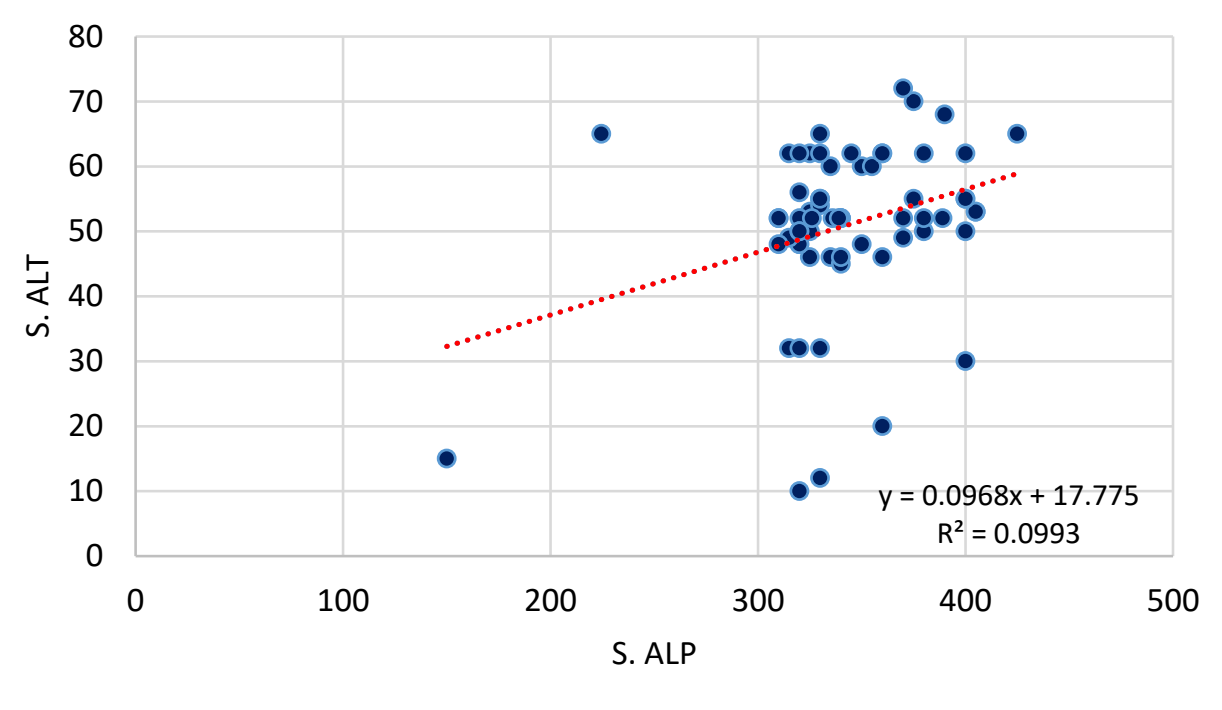

Figure 4. Linear Regression: S. ALP vs S. ALT enzyme. 